\section{(2) OPEN ACCESS}

\title{
Influence of changing working conditions on exit from paid employment among workers with a chronic disease
}

\author{
Jolinda L D Schram (1) ,' Suzan J W Robroek, ${ }^{1}$ Patricia Ots (1), ${ }^{2}$ Sandra Brouwer, ${ }^{2}$ \\ Alex Burdorf, ${ }^{1}$ Sander K R van Zon (1) , ${ }^{2}$ Karen M Oude Hengel (1) ${ }^{1,3}$
}

\begin{abstract}
- Additional material is published online only. To view please visit the journal online (http://dx.doi.org/10.1136/ oemed-2019-106383).

'Department of Public Health, Erasmus University Medical Center, Rotterdam, The Netherlands

2Department of Health Sciences, Community \& Occupational Medicine, University Medical Center Groningen, Groningen, The Netherlands

${ }^{3}$ Work, Health \& Technology, Netherlands Organization for Applied Scientific Research TNO, Leiden, The Netherlands
\end{abstract}

Correspondence to Dr Karen M Oude Hengel, Department of Public Health, Erasmus University Medical Center, Rotterdam 3000 CA, The Netherlands;

k.oudehengel@erasmusmc.nl

Received 20 December 2019 Revised 20 March 2020 Accepted 21 April 2020 Published Online First 21 May 2020

\section{ABSTRACT}

Objectives To investigate the relation between changes in working conditions and exit from paid employment among workers with a chronic disease. Methods Six waves from the longitudinal Study on Transitions in Employment, Ability and Motivation (20102016), enriched with tax-based employment information from Statistics Netherlands (2011-2017), were available for 4820 chronically ill workers aged $45-63$ years (mean 55.3 years, SD 5.1). A change in working conditions (physical workload, psychological job demands, job autonomy, emotional job demands and social support) was defined as an increase or decrease between two consecutive waves of at least one SD. Discrete-time survival models with repeated measurements were used to estimate the relative risk (RR) of a change in working conditions on exiting paid employment in the following year compared with no change and consecutive favourable working conditions.

Results A favourable change in physical workload lowered the risk to exit paid employment (RR 0.46, $95 \% \mathrm{Cl} 0.22$ to 0.94$)$. An adverse change in psychosocial working conditions, especially a decrease in social support (RR 2.07, 95\% CI 1.52 to 2.81), increased the likelihood to exit paid employment. In contrast, a favourable change in psychological job demands increased the risk to exit paid employment (RR 1.57, $95 \% \mathrm{Cl} 1.09$ to 2.24). Multiple adverse changes increased the risk to exit paid employment up to six times (RR 6.06, 95\% Cl 2.83 to 12.98).

Conclusions Changes in working conditions among workers with chronic diseases influence exit from paid employment. Ensuring that working conditions can be adapted to the needs of workers with a chronic disease may help to extend working life.

\section{INTRODUCTION}

Check for updates

(C) Author(s) (or their employer(s)) 2020. Re-use permitted under CC BY-NC. No commercial re-use. See rights and permissions. Published by BMJ.

\begin{tabular}{l}
\hline To cite: Schram JLD, \\
Robroek SJW, Ots $\mathrm{P}_{1}$ \\
et al. Occup Environ Med \\
2020;77:628-633. \\
\hline
\end{tabular}

In recent decades, policy changes have stimulated workers to stay in the workforce until a higher age. In the Netherlands, older workers aged 60-65 years have increased their participation in paid employment from $33.2 \%$ in 2008 to $58.1 \%$ in $2018,{ }^{1}$ but this is mainly attributed to workers being in good health. ${ }^{2}$ Participation in paid employment is considerably lower among persons with a chronic disease compared with those without. ${ }^{3}$ Alongside an ageing workforce, the number of workers with a chronic disease is rising. Workers with a chronic disease are more likely, in comparison to healthy

\section{Key messages}

What is already known about this subject?

- Workers with a chronic disease are at a higher risk to exit paid employment than workers without a chronic disease.

- Low physical workload is related to being in paid employment for workers with a chronic disease, while low social support is an important risk factor for exit from paid employment.

- Adverse changes in physical and psychosocial working conditions contribute to sickness absence and ill health.

What are the new findings?

- The risk of exit from paid employment decreased with a favourable change in physical workload and increased with adverse changes in social support at work among workers with a chronic disease.

- In contrast, a favourable change in psychological job demands increased the risk of exit from paid employment compared to no change in these demands.

- Multiple adverse changes increased the risk of exit from paid employment up to six times, while multiple favourable changes did not have a cumulative effect.

How might this impact on policy or clinical practice in the foreseeable future?

- Work(place) adjustments for workers with a chronic disease could help prevent early exit from paid employment.

colleagues, to take sick leave or to become unemployed. $^{56}$

In general, adverse physical and psychosocial working conditions are associated with premature exit from paid employment. ${ }^{7}$ Studies among persons with a chronic disease reported that unfavourable working conditions such as high physical workload ${ }^{8}$ or demanding psychosocial working conditions ${ }^{6} 8$ increased the risk of exit from paid employment, ${ }^{6}$ such as through disability and unemployment. ${ }^{8}$ Another study showed that high job autonomy and high social support at work reduced the risk of exit from paid employment. ${ }^{9}$ Also, lack of social 


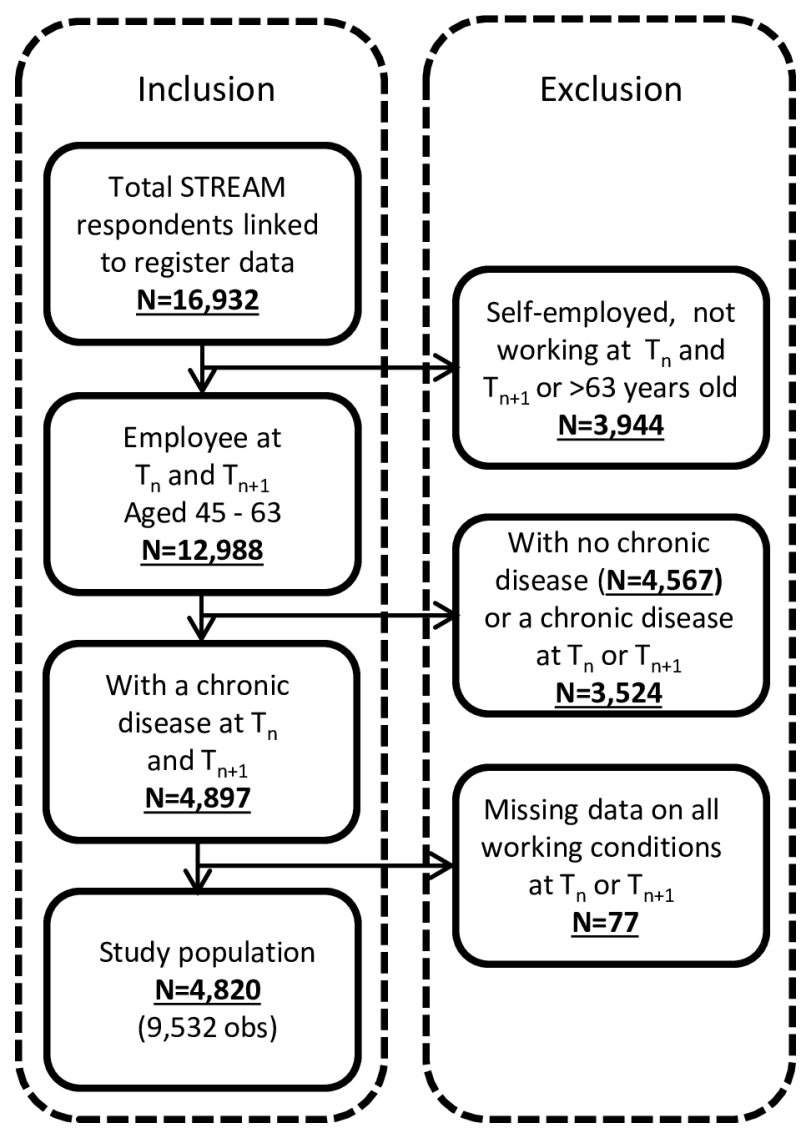

Figure 1 Flow chart study population. STREAM, Study on Transitions in Employment, Ability and Motivation.

support at work increased the likelihood to exit paid employment only for workers with a chronic disease. ${ }^{10}$ The aforementioned studies suggest that the influence of working conditions on loss of paid employment may be different for workers with a chronic disease. Since workers with chronic diseases may differ in many aspects from those without chronic diseases, measured and unmeasured, it is of interest to specifically evaluate associations of working conditions and exit from paid employment within workers with a chronic disease.

A work environment with favourable working conditions seems encouraging for workers with a chronic disease to remain in paid employment. However, this evidence is almost exclusively based on studies that link exposure level at baseline with loss of paid employment during the follow-up. Such a design is sensitive to selection processes whereby healthier workers are over-represented at enrolment, and, thus, conclusions may be biased. A potential strategy to reduce the risk of bias is to focus on the effects of changes in working conditions rather than magnitude of working conditions on exit from paid employment. Several studies have investigated whether adverse and favourable changes in physical and psychosocial working conditions contribute to sickness absence (SA), ${ }^{11-13}$ physical functioning ${ }^{14}$ or self-rated health. ${ }^{15}$ Favourable changes in physical working conditions were associated with less SA, ${ }^{13}$ while adverse changes had the opposite effect. Results for psychosocial working conditions were mixed, adverse changes in job autonomy were associated with a decline in physical functioning and favourable changes reduced the decline, while changes in psychological job demands showed no effect. ${ }^{14}$ Studies on SA showed that an increase in psychological job demands ${ }^{11}$ and a decrease of autonomy ${ }^{11} 13$ increased the risk of SA while more social support at work lowered the risk of SA. ${ }^{11}$ Adverse changes in psychological job demands and job autonomy had a negative effect on self-rated health for males. ${ }^{15}$ Given these studies on effects of changing working conditions on SA and health, there is a clear need for studies addressing the important question on how adverse or favourable changes in working conditions will influence exit from paid employment, particularly among workers with a chronic disease.

The aim of this study is to gain insight in the relation between changes in physical and psychosocial working conditions and exit from paid employment among workers with a chronic disease and to determine whether multiple changes in working conditions have an additive or multiplicative effect on exit from paid employment.

\section{METHODS}

\section{Study design}

This longitudinal study was embedded in the Dutch longitudinal Study on Transitions in Employment, Ability and Motivation (STREAM) from 2010 onwards. Participants aged 45 years and older filled out an online questionnaire annually in the years 2010-2013, 2015-2017 and 2019. In 2010, 15118 respondents participated, and in 2015, an additional sample of 6738 participants was added. The study population of STREAM has been extensively described elsewhere. ${ }^{16}$ The Medical Ethical Committee of the VU University Medical Centre Amsterdam declared that the Medical Research Involving Human Subjects Act does not apply to STREAM. STREAM data were enriched by Statistics Netherlands with information on the main income components, social benefit pensions and gross wages, derived from the Dutch tax registers and stored in the social statistical database (SSB). ${ }^{17}$ STREAM data up to 2016 were matched with monthly information from SSB (November 2011 until December 2017).

\section{Study population}

Of the 21856 STREAM participants, 18896 gave permission, by explicit informed consent, to link the questionnaire data to register data of Statistics Netherlands. For the current study, participants were selected aged 45-63 at baseline, who were not self-employed and working, based on the tax register data, for at least two consecutive years $(n=12988)$. Additionally, participants were selected if they had a chronic disease during these two consecutive years $(n=4897)$. Participants could be included with multiple measurements. The final analytical sample included 9532 observations from 4820 participants (figure 1).

\section{Chronic disease}

The presence of a chronic health problem was assessed at baseline $\left(T_{n}\right)$ and $T_{n+1}$ using the following question, 'Do you (currently) have one or more of the following chronic diseases, disorders or handicaps?' (3). Fifteen answer options were provided of which six major chronic diseases were defined by their prevalence ${ }^{18}$ : diabetes mellitus, cardiovascular, digestive, psychological, musculoskeletal and respiratory diseases. Different musculoskeletal disorders were classified into one category. Subjects with migraine, skin problems, hearing problems, eye problems, epilepsy and life-threatening diseases were excluded from the analysis following previous studies. ${ }^{19}$ 


\section{Working conditions}

Physical workload, psychological job demands, job autonomy, emotional job demands and social support at work were assessed at $T_{n}$ and $T_{n+1}$. Physical workload included five items on force exertion, static load (standing, posture and kneeling) and vibration (Cronbach's alpha 0.86). ${ }^{20}$ Psychological job demands was assessed with four Job Content Questionnaire (JCQ) items on how fast, how much, how hard and how hectic an individual's work is (Cronbach's alpha 0.91). ${ }^{21}$ Autonomy was measured with five JCQ items about making decisions, deciding the order and speed of conducting tasks, having to find solutions and being able to take time off (Cronbach's alpha 0.78). ${ }^{21}$ Emotional job demands were assessed with three items from the Copenhagen Psychosocial Questionnaire (COPSOQ) about emotionally difficult situations, emotional demands and emotional involvement at work (Cronbach's alpha 0.86). ${ }^{22}$ Social support at work was assessed with four COPSOQ items concerning how often colleagues and supervisor are willing to help, support and listen to work-related problems (Cronbach's alpha 0.81). ${ }^{22}$ All items had a 5-point answer scale ranging from 'always' to '(almost) never'. The answer categories were recoded so that a higher sum score equalled higher exposure to poor working conditions.

An SD for each working condition was calculated based on the baseline sample with the first observation of each included individual. Having a change in a working condition between two consecutive annual measurements was calculated as the difference between the score of a working condition at $T_{n+1}$, minus the score of the working condition at $\mathrm{T}_{\mathrm{n}}$. If this difference was higher than SD at baseline, this was defined as a change in working conditions. Individuals were divided into four categories: (1) those with less than 1 SD change in working conditions between two measurements and an exposure below the mean at baseline (the reference category, consecutive favourable), (2) those with less than 1 SD change in working conditions between two measurements and an exposure above or at the mean at baseline (consecutive adverse), (3) those with a favourable change of 1 $\mathrm{SD}$ or more in working conditions between two measurements and (4) those with an adverse change of 1 SD or more in working conditions between two measurements.

\section{Exit from paid employment}

Based on information from Statistics Netherlands on the main income component, ${ }^{17}$ an exit from paid employment in the 12 months following $T_{n+1}\left(T_{n+2}\right)$ was defined. Exit from paid employment was defined by a period of at least three consecutive months out of paid employment during follow-up of 14 months.

\section{Covariates}

Age, sex, educational level, marital status, contract hours and multimorbidity at baseline were included as covariates. Education was measured with a question on the highest level of education completed, and categorised into low (primary school, lower and intermediate secondary school or lower vocational training), intermediate (higher secondary school or intermediate vocational training) and high (higher vocational education or university education). Marital status was used to categorise individuals into those living together with a spouse or partner in the same household and others (ie, those living alone). Contract hours were measured with the question 'How many hours per week do you work according to your contract?'. Multimorbidity was assessed based on the previously mentioned question on chronic diseases, that is, those who indicated to have more than
Table 1 Sociodemographic characteristics, health and working conditions among Dutch workers with a chronic disease (first observations, $\mathrm{n}=4820$ )

\begin{tabular}{|c|c|c|}
\hline & Total* & $\%$ imputed \\
\hline Women & $47 \%$ & \\
\hline Age (mean, SD) & $55.29(5.09)$ & \\
\hline Married or cohabitating & $76 \%$ & \\
\hline \multicolumn{3}{|l|}{ Education } \\
\hline Low & $27 \%$ & \\
\hline Mid & $40 \%$ & \\
\hline High & $33 \%$ & \\
\hline \multicolumn{3}{|l|}{ Chronic disease } \\
\hline Musculoskeletal disorders & $65 \%$ & \\
\hline Digestive disorders & $13 \%$ & \\
\hline Respiratory disorders & $16 \%$ & \\
\hline Diabetes & $14 \%$ & \\
\hline Psychological disorders & $8 \%$ & \\
\hline Heart disease & $20 \%$ & \\
\hline Multimorbidity & $29 \%$ & \\
\hline Contract hours per week (mean, SD) & $31.38(9.31)$ & 0.26 \\
\hline \multicolumn{3}{|c|}{ Working conditions-mean and SD—scale 1 to 5} \\
\hline Physical workload & $1.88(0.92)$ & 0.51 \\
\hline Psychological job demands & $3.21(0.77)$ & 0.41 \\
\hline Job autonomy & $2.24(0.72)$ & 0.19 \\
\hline Emotional job demands & $2.53(0.85)$ & 1.33 \\
\hline Social support at work & $2.45(0.78)$ & 0.12 \\
\hline \multicolumn{3}{|c|}{ Exit of paid employment between $T_{n+1}$ and $T_{n+2} \%(n)$} \\
\hline Total exit of paid employment & 8 & \\
\hline Early retirement & $3(148)$ & \\
\hline Unemployment & $3(139)$ & \\
\hline Disability benefits & $1(44)$ & \\
\hline Economic inactivity & $1(29)$ & \\
\hline
\end{tabular}

${ }^{*}$ Total from the non-imputed dataset.

one of the six included chronic diseases were considered having multimorbidity.

\section{Statistical analyses}

Missing variables on working conditions and individual characteristics (ranging from $0.19 \%$ to $1.34 \%$; table 1 ) were imputed using multiple imputation by chained equations $(M=20)$. Descriptive statistics were based on the individual's first included observation.

The effects of changing working conditions between two consecutive measurements $\left(T_{n}\right.$ and $\left.T_{n+1}\right)$ on exit from paid employment (between $T_{n+1}$ and $T_{n+2}$ ) were analysed with discrete-time survival models. ${ }^{23}$ This approach allowed for multiple observations per individual by including a random factor for each participant. If the working conditions changed between $T_{n}$ and $T_{n+1}$, the model calculated the probability that an individual exited paid employment between $T_{n+1}$ and $T_{n+2}$, compared with those without a change and consecutive favourable working conditions between $T_{n}$ and $T_{n+1}$. This approach ensured that the change in working conditions preceded the risk of loss of paid employment. If individuals turned 65 years of age between $T_{n+1}$ and $T_{n+2}$, they were censored from the moment they turned 65 , as this was the main statutory retirement age during the period of the data collection (2010-2016). If data were missing from the registries, subjects were also censored. 
Table 2 Relative risk of exit from paid employment of workers with a chronic disease with at least a 1 SD change in working conditions compared with those without change and consecutive favourable working conditions (total population, $n=4820$, observations=9532)

\begin{tabular}{|c|c|c|c|}
\hline & $\%$ total study population & $\begin{array}{l}\% \text { exit from paid employment } \\
\text { between } T_{n+1} \text { and } T_{n+2}\end{array}$ & $\begin{array}{l}\text { Model }^{*} \\
\text { relative risk }(95 \% \mathrm{Cl})\end{array}$ \\
\hline Physical workload—consecutive favourable & 57.7 & 7.9 & 1 \\
\hline Physical workload—consecutive adverse & 37.2 & 7.1 & 0.94 (0.75 to 1.18$)$ \\
\hline Physical workload_favourable change & 2.4 & 4.3 & 0.46 (0.22 to 0.94$)$ \\
\hline Psychological job demands—consecutive favourable & 40.9 & 7.4 & 1 \\
\hline Psychological job demands_favourable change & 5.4 & 11.4 & 1.57 (1.09 to 2.24$)$ \\
\hline Job autonomy-consecutive favourable & 53.8 & 7.1 & 1 \\
\hline Job autonomy—consecutive adverse & 32.5 & 7.3 & $1.08(0.86$ to 1.35$)$ \\
\hline Job autonomy_adverse change & 7.0 & 9.9 & 1.38 (0.99 to 1.93$)$ \\
\hline Job autonomy_favourable change & 6.7 & 8.9 & 1.25 (0.87 to 1.77$)$ \\
\hline Social support at work—consecutive favourable & 39.7 & 6.6 & 1 \\
\hline Social support at work—consecutive adverse & 44.4 & 7.7 & 1.14 (0.91 to 1.41$)$ \\
\hline Social support at work-adverse change & 8.6 & 11.4 & 2.07 (1.52 to 2.81$)$ \\
\hline Social support at work_-favourable change & 7.3 & 7.0 & $1.08(0.74$ to 1.56$)$ \\
\hline
\end{tabular}

*Adjusted for age, sex, educational level, contract hours, marital status and multimorbidity.

The Stata command 'xtmepoisson' was used to estimate relative risks (RRs) of exit from paid employment of persons with a $1 \mathrm{SD}$ change in working conditions compared with those without change and with consecutive favourable working conditions. This procedure fits a random intercept Poisson regression model with repeated observations nested within individuals, and time at risk as a log offset. A RR greater than one indicated an increased likelihood of exit from paid employment. Models were adjusted for age, sex, educational level, contract hours and multimorbidity. Analyses were conducted for all participants with a chronic disease and interaction was tested for sex and education.

Furthermore, sensitivity analyses were performed to explore whether the results for exit from paid employment differed for participants without any of the chronic diseases. The analyses were conducted using Stata V.15.1.

\section{RESULTS}

The study population consisted of 4820 workers with a chronic disease, of which $29 \%$ reported two or more chronic diseases (table 1). Musculoskeletal diseases were most prevalent (65\%), followed by cardiovascular diseases (20\%). On average, the study population worked 31.38 hours a week (SD 9.31). Working conditions that stood out were high psychological job demands (mean 3.21 SD 0.77) and low physical working conditions (mean 1.88 SD 0.92) at baseline. Between $\mathrm{T}_{\mathrm{n}+1}$ and $\mathrm{T}_{\mathrm{n}+2}, 8 \%$ exited paid employment, mostly via early retirement or unemployment.

Most changes in working conditions among workers with a chronic disease were found for emotional job demands (17.8\%, table 2), followed by social support at work (15.8\%). Only 5\% had a change in physical workload. Given the observed SD values, a change in working conditions was effectively a change towards a higher or lower score on the 5 point scale. Of those with an adverse change in physical workload, 8.6\% exited paid employment between $T_{n+1}$ and $T_{n+2}$, while among those with a favourable change in physical workload only $4.3 \%$ exited paid employment. The highest percentage of exit from paid employment between $T_{n+1}$ and $T_{n+2}$ was among persons who had an adverse change in social support at work and a favourable change in psychological job demands (11.4\%), and an adverse change in emotional job demands (10.5\%).

Workers with a favourable change in physical workload had a lower risk to exit paid employment compared with those without change and consecutive favourable physical workload (RR $0.46,95 \%$ CI 0.22 to 0.94 ) (table 2). An adverse change in social support at work (RR 2.07, 95\% CI 1.52 to 2.81), emotional job demands (RR 1.34, 95\% CI 0.98 to 1.83) and job autonomy (RR $1.38,95 \%$ CI 0.99 to 1.93 ) increased the risk of exit from paid employment. In contrast, a favourable change in psychological job demands was also associated with a higher risk of exit from paid employment (RR 1.57, 95\% CI 1.09 to 2.24). Having consecutive adverse working conditions compared with consecutive favourable did not significantly modify the risk to exit paid employment. Interactions with sex or education were not statistically significant, except for education with autonomy and physical workload. Intermediate and higher educated workers had a lower risk to exit paid employment with consecutive adverse physical workload and consecutive adverse autonomy than low educated workers (Results are not shown).

When analysing multiple changes at the same time, about half of the study population (52.7\%) had no change in any working conditions and $8 \%$ had both favourable as well as adverse changes (table 3 ). Workers with one adverse change had an increased risk of exit from paid employment compared with those without any change (RR $1.54,95 \%$ CI 1.21 to 1.98 ). This risk increased additively for those with three or more adverse changes in working conditions to RR 6.06 (95\% CI 2.83 to 12.98). For favourable changes, there was no additive trend with lower risks for exit from paid employment with more improvements in working conditions. 
Table 3 Relative risk of exit from paid employment of workers with a chronic disease with multiple favourable or adverse changes of at least 1 SD compared with those without any change (total population, $\mathrm{n}=4820$, observations 9532)

\begin{tabular}{|c|c|c|c|}
\hline & $\begin{array}{l}\% \text { total } \\
\text { study } \\
\text { population }\end{array}$ & $\begin{array}{l}\% \text { exit } \\
\text { from paid } \\
\text { employment } \\
\text { between } T_{n+1} \\
\text { and } T_{n+2}\end{array}$ & $\begin{array}{l}\text { Model } \\
\text { relative risk (95\% } \\
\text { Cl) }\end{array}$ \\
\hline No changes & 52.7 & 6.3 & 1 \\
\hline $\begin{array}{l}\text { Three or more favourable } \\
\text { changes }\end{array}$ & 0.7 & 10.0 & 1.25 (0.49 to 3.18$)$ \\
\hline Two favourable changes & 2.8 & 8.1 & $1.29(0.75$ to 2.21$)$ \\
\hline One favourable change & 15.5 & 7.9 & 1.33 (1.03 to 1.72$)$ \\
\hline One adverse change & 16.4 & 8.7 & 1.54 (1.21 to 1.98$)$ \\
\hline Two adverse changes & 3.2 & 10.7 & 1.75 (1.10 to 2.78$)$ \\
\hline $\begin{array}{l}\text { Three or more adverse } \\
\text { changes }\end{array}$ & 0.6 & 23.3 & 6.06 (2.83 to 12.98$)$ \\
\hline $\begin{array}{l}\text { Both favourable and } \\
\text { adverse changes }\end{array}$ & 8.0 & 9.4 & 1.48 (1.06 to 2.05$)$ \\
\hline
\end{tabular}

The sensitivity analyses among workers without any of the chronic diseases showed a similar picture for changing psychosocial working conditions compared with those with a chronic disease, both concerning the prevalence of changing working conditions as the strength of the associations (online supplementary table 1 ). In contrast to workers with a chronic disease, having consecutive adverse working conditions seemed to reduce the risk to exit paid employment, although not statistically significant. Also, among this group, a favourable change in physical workload did not reduce the risk of exiting paid employment the following year compared with persons without a change and consecutive favourable physical workload. Analysing multiple changes, for workers without a chronic disease, both multiple favourable and multiple adverse changes in working conditions seemed to increase the risk of exiting paid employment between $\mathrm{T}_{\mathrm{n}+1}$ and $\mathrm{T}_{\mathrm{n}+2}$ (online supplementary table 2 ).

\section{DISCUSSION}

The influence of changes in working conditions on exit from paid employment among workers with a chronic disease differed across working conditions. Reduced physical workload decreased the risk of exit from paid employment compared with those without change and consecutive favourable physical workload. An adverse change in social support at work increased the risk of exit from paid employment. Changes in psychological job demands were an exceptional case, as an improvement in psychological job demands was associated with an increased risk to exit paid employment. The more adverse changes in working conditions, the higher the risk of exit from paid employment.

The findings on the effects of changes in physical and psychosocial working conditions on labour force participation confirm most of the previous studies investigating the effects of the magnitude of working conditions on exit from paid employment among workers with a chronic disease. ${ }^{69102425}$ For instance, low social support is an important risk factor for exit from paid employment. ${ }^{910}$ The current study underpins the existing knowledge by showing the effects of favourable and adverse changes in both physical and psychosocial working conditions, which is less sensitive to selection bias. This evidence is important for the prevention of early exit from paid employment among workers with a chronic disease as it offers novel insights into the potential of improving working conditions.

Bearing in mind that working conditions are modifiable aspects of work, it is important to know whether changes in working conditions can influence the risk to exit paid employment for workers with a chronic disease. The effects of favourable and adverse changes in working conditions did not mirror each other. For physical workload, we observed a decreased risk with reduced exposure, but no significant increased risk with higher exposure. For social support, we observed an opposite pattern, whereby an adverse change was associated with higher exit risk, while a favourable change had no effect on the exit risk. These findings cannot be explained by differences in the prevalence of changes in exposure, since in our study population similar proportions of workers experienced improvements as deteriorations in working conditions. Further research is needed to investigate whether characterisation of changes in absolute magnitude of exposure is to be preferred over our approach with changes on a relative scale, expressed by 1 SD.

A surprising finding was that a favourable change in psychological job demands, largely reflecting less work pressure, and to a lesser extent higher job autonomy, increased the risk of exit from paid employment. A previous study also found these counterintuitive results, reporting that demanding psychosocial working conditions protected against job loss during sick leave. ${ }^{26}$ It can be hypothesised that when a worker experiences functional limitations, psychological job demands are perhaps lowered as a last resource to prevent exit from paid employment. If a disease is increasingly limiting and changes in working conditions take place late in the development of the disease, exit from paid employment may be likely either way, regardless of favourable changes in working conditions. Further research is needed, as information on functional limitations was not available in this dataset.

Multiple favourable changes did not affect the risk of exit from paid employment, while multiple adverse changes did increase the risk up to six times. Thus, the direction of the change is important to include in the analyses. However, there are limitations using self-reported working conditions. It cannot be fully ruled out that an individuals' perception or reporting of working conditions was influenced by the disease status. If a worker experienced functional limitations due to a chronic disease, they may also report an adverse change in working conditions, while objectively no change occurred. ${ }^{27}$ However, there are no differences in the amount of changes for the chronically ill population compared with the healthy population. Nevertheless, from the data it cannot be derived whether the changes took place due to the chronic disease or if they are independent of having a chronic disease. More research is needed on workers with incident cases of a chronic disease, which was not possible in the current study population.

Several strengths and limitations need to be considered. First, the study design, using a large representative national sample with a combination of self-reported and register data for analysis, is a strength, and it applied a considerable change (1 SD from baseline) in exposure as the variable of interest. The short 1-year follow-up time is a strength, as it could be hypothesised that a change in working conditions took place close to the event. In an earlier study on a change in working conditions and its effect on health outcomes, the strength of the association was stronger with 1 or 2 years follow-up than after 7-10 years follow-up. ${ }^{28}$

Some limitations should be considered as well. First, chronic disease and working conditions are based on self-reports. For chronic diseases, the question does not specify whether the 
health issue was diagnosed by a physician and there is no information on functional limitations or severity of the disease. For working conditions, self-reported working conditions make it difficult to distinguish between actual change in working conditions and within-person deviations. ${ }^{29}$ However, when using a considerable change in working conditions, it can be reasonably expected that working conditions have changed substantially from the previous measurement and are not the result of merely within-person deviations in self-assessments. Second, some working conditions had a skewed distribution, that is, for physical workload most persons had a score of 1 on the 5 point scale. However, since change was analysed, the distribution was not skewed, having a favourable change was as likely as an adverse change. Third, adjustments of working conditions might not be equally important for all chronic diseases, as illnesses differ in impact on work. However, a previous study showed a comparable impact of working conditions on exit from paid employment across various chronic diseases. ${ }^{8}$ Lastly, the study population was too small to analyse whether a change in working conditions would have different effects on different exit routes, such as early retirement or unemployment.

In conclusion, this study indicates that improvements in physical working conditions may reduce the risk of exit from paid employment for chronically ill workers. Deteriorating physical and psychosocial working conditions, on the other hand, increased the risk of exit, and more adverse changes increased the risk of exit.

Contributors JLDS, SJWR, AB and $\mathrm{KMOH}$ designed the model and the analytical framework. JLDS analysed the data and performed the analyses. After the first analysis the analytical model was discussed by JLDS, SJWR, PO, SB, AB, SKRvZ and $\mathrm{KMOH}$ and improved. JLDS drafted the manuscript with input from all authors. The final version has been approved by all authors.

Funding This study was funded by ZonMw (http://dx.doi.org/10.13039/ 501100001826) and grant number: 531001411.

Competing interests None declared.

Patient consent for publication Not required.

Provenance and peer review Not commissioned; externally peer reviewed.

Data availability statement Data are stored at Statistics Netherlands. Data are available on reasonable request, following the guidelines of the Statistics Netherlands.

Open access This is an open access article distributed in accordance with the Creative Commons Attribution Non Commercial (CC BY-NC 4.0) license, which permits others to distribute, remix, adapt, build upon this work non-commercially, and license their derivative works on different terms, provided the original work is properly cited, appropriate credit is given, any changes made indicated, and the use is non-commercial. See: http://creativecommons.org/licenses/by-nc/4.0/.

\section{ORCID iDs}

Jolinda L D Schram http://orcid.org/0000-0002-6856-1897

Patricia Ots http://orcid.org/0000-0001-5587-4985

Sander K R van Zon http://orcid.org/0000-0002-1956-1225

Karen M Oude Hengel http://orcid.org/0000-0003-3745-2660

\section{REFERENCES}

1 CBS. StatlLine - Arbeidsdeelname. kerncijfers: Centraal Bureau voor de Statistiek, 2019

2 García-Gómez P, von Gaudecker H-M, Lindeboom M. Health, disability and work: patterns for the working age population. Int Tax Public Financ 2011;18:146-65.

3 Minton JW, Pickett KE, Dorling D. Health, employment, and economic change, 19732009: repeated cross sectional study. BMJ 2012;344:e2316.

4 Schram JLD, Schuring M, Oude Hengel KM, et al. Health-Related educational inequalities in paid employment across 26 European countries in 2005-2014: repeated cross-sectional study. BMJ Open 2019;9:e024823.
5 Schuring M, Burdorf L, Kunst A, et al. The effects of ill health on entering and maintaining paid employment: evidence in European countries. J Epidemiol Community Health 2007;61:597-604.

6 Boot CRL, Deeg DJH, Abma T, et al. Predictors of having paid work in older workers with and without chronic disease: a 3-year prospective cohort study. J Occup Rehabil 2014;24:563-72.

7 Robroek SJW, Schuring M, Croezen S, et al. Poor health, unhealthy behaviors, and unfavorable work characteristics influence pathways of exit from paid employment among older workers in Europe: a four year follow-up study. Scand I Work Environ Health 2013;39:125-33.

8 Leiiten FRM, de Wind A, van den Heuvel SG, et al. The influence of chronic health problems and work-related factors on loss of paid employment among older workers. J Epidemiol Community Health 2015;69:1058-65.

9 Fleischmann M, Carr E, Stansfeld SA, et al. Can favourable psychosocial working conditions in midlife moderate the risk of work exit for chronically ill workers? A 20 year follow-up of the Whitehall II study. Occup Environ Med 2018;75:183-90.

10 de Boer AGEM, Geuskens GA, Bültmann U, et al. Employment status transitions in employees with and without chronic disease in the Netherlands. Int J Public Health 2018:63:713-22

11 Head J, Kivimäki M, Martikainen P, et al. Influence of change in psychosocial work characteristics on sickness absence: the Whitehall II study. J Epidemiol Community Health 2006;60:55-61.

12 Milner A, Butterworth P, Bentley R, et al. Sickness absence and psychosocial job quality: an analysis from a longitudinal survey of working Australians, 2005-2012. Am J Epidemiol 2015;181:781-8.

13 Saastamoinen P, Laaksonen M, Lahelma E, et al. Changes in working conditions and subsequent sickness absence. Scand J Work Environ Health 2014;40:82-8.

14 Mänty M, Kouvonen A, Lallukka T, et al. Changes in working conditions and physical health functioning among midlife and ageing employees. Scand $J$ Work Environ Health 2015:41:511-8.

15 Milner A, Witt K, Spittal MJ, et al. The relationship between working conditions and self-rated health among medical doctors: evidence from seven waves of the medicine in Australia balancing employment and life (MABEL) survey. BMC Health Serv Res 2017;17:609.

16 Ybema J. Study on transitions in employment, ability and motivation (stream): the design of a four-year longitudinal cohort study among 15,118 persons aged 45 to 64 years. Br J Med Med Res 2014;4:1383-99.

17 Bakker BFM, Van Rooijen J, Van Toor L. The system of social statistical datasets of statistics Netherlands: an integral approach to the production of register-based social statistics. Statistical journal of the United Nations ECE 2014;30:411-24.

18 Virtanen M, Ervasti J, Head J, et al. Lifestyle factors and risk of sickness absence from work: a multicohort study. Lancet Public Health 2018;3:e545-54.

19 Oude Hengel K, Robroek SJW, Eekhout I, et al. Educational inequalities in the impact of chronic diseases on exit from paid employment among older workers: a 7-year prospective study in the Netherlands. Occup Environ Med 2019;76:718-25.

20 Bot SDM, Terwee CB, van der Windt DAWM, et al. Internal consistency and validity of a new physical workload questionnaire. Occup Environ Med 2004;61:980-6.

21 Karasek R, Brisson C, Kawakami N, et al. The job content questionnaire (JCQ): an instrument for internationally comparative assessments of psychosocial job characteristics. J Occup Health Psychol 1998:3:322-55.

22 Kristensen TS, Hannerz H, Høgh A, et al. The Copenhagen Psychosocial Questionnaire-a tool for the assessment and improvement of the psychosocial work environment. Scand J Work Environ Health 2005:31:438-49.

23 Steele F, Goldstein H, Browne W. A general multilevel multistate competing risks model for event history data, with an application to a study of contraceptive use dynamics. Stat Model 2004;4:145-59.

24 Sewdas R, van der Beek AJ, de Wind A, et al. Determinants of working until retirement compared to a transition to early retirement among older workers with and without chronic diseases: results from a Dutch prospective cohort study. Scand I Public Health 2018:46:400-8.

25 Koolhaas W, van der Klink JJL, Vervoort JPM, et al. In-Depth study of the workers' perspectives to enhance sustainable working life: comparison between workers with and without a chronic health condition. J Occup Rehabil 2013;23:170-9.

26 Flach PA, Groothoff JW, Bültmann U. Identifying employees at risk for job loss during sick leave. Disabil Rehabil 2013;35:1835-41

27 Fleischmann M, Carr E, Xue B, et al. Changes in autonomy, job demands and working hours after diagnosis of chronic disease: a comparison of employed and self-employed older persons using the English longitudinal study of ageing (ELSA).J Epidemiol Community Health 2018;72:951-7.

28 Smith PM, Bielecky A. The impact of changes in job strain and its components on the risk of depression. Am J Public Health 2012;102:352-8.

29 Smith P, Beaton D. Measuring change in psychosocial working conditions: methodological issues to consider when data are collected at baseline and one follow-up time point. Occup Environ Med 2008;65:288-96. 